\title{
Modified Fuzzy Forecasting Approach for Student Enrollment Series
}

\author{
Muhammad Ullah $^{1}$, Farhadur Reza $^{2}$, AzizurRahman $^{3 *}$ and Mariam Akter ${ }^{4}$ \\ ${ }^{1}$ Assistant Professor, Department of Philosophy, Jahangirnagar University, \\ Savar, Bangladesh \\ ${ }^{2}$ Assistant Professor, Department of Urban and Regional Planning, \\ Jahangirnagar University, Savar, Bangladesh \\ ${ }^{3}$ Assistant Professor, Department of Statistics, Jahangirnagar University, \\ Savar, Bangladesh \\ ${ }^{4}$ Ex-teaching Assistant, United International University, Dhaka, Bangladesh \\ ${ }^{1}$ muhammad@juniv.edu, ${ }^{2}$ farhadrezaurp@juniv.edu, ${ }^{3} a z i z u r @ j u n i v . e d u$ \\ 4mariam.rahman@gmail.com
}

\begin{abstract}
Student enrollment forecasting provides significant information for management in decision making and planning for the institutions of higher education. Nowadays, a modified fuzzy method is used among many other existing methods proposed for forecasting enrollment based on fuzzy time series. Because, the forecasting accuracy rates of the existing methods are not adequate enough. In this paper, a modified fuzzy method is used to forecast enrollment based on fuzzy time series on the enrollment data of Philosophy Department in Jahangirnagar University, Bangladesh. The proposed method yields a higher forecasting accuracy rate and suggests a good choice of forecasting method for effective and efficient management for the institutions of higher education.
\end{abstract}

Keywords: fuzzy time series, forecasting, forecasting accuracy rate, student enrollment, policy making

\section{Introduction}

For efficient and effective management, forecasting is considered as a critical tool for strategic as well as tactical decision making [3]. In developed countries, educational institutions use different statistical models to project the number of students to enroll in a certain course or year level [6]. Enrollment forecasting is related to analyzing current trends, understanding the significant impact on the enrollment and revenue outcomes [14]. Predicting the number of students is thus important for estimating the distributed budget into academic institution. It may contribute in formulating strategic and action plan and may be used as information for adopting long term policy [2, $6 \& 14]$.

Classical time series requires many assumptions such as the normality of data, linearity in the auto-correlation coefficient, and statistical parameter estimators. It is almost impossible to find all these assumptions applicable in stochastic time series generation or simulation. But linguistic uncertainties by the fuzzy sets have opened a wide spectrum of applications in diverse fields [17]. Fuzzy application areas include estimation, prediction, control, approximate reasoning, intelligent system design, machine learning, image processing, machine vision, pattern reorganization, medical computing, civil, chemical

Received (May 25, 2017), Review Result (August 29, 2017), Accepted (September 9, 2017)

* Corresponding Author 
and industrial engineering [13]. This paper, therefore, is an endeavor to forecast student enrollment by the application of Fuzzy model at the Department of Philosophy in Jahangirnagar University, Bangladesh.

\section{Literature Review}

It is evident that forecasting activities play an important role in decision making. The classical time series methods cannot deal with forecasting problems in which the values of time series are linguistic terms represented by fuzzy sets [16]. Therefore, in their paper, Song and Chissom [8] describe the theory of fuzzy time series methodology to get an advantage over the classical time series. Song et al. present some forecasting methods $[11,8,9,10]$ to forecast the enrollment of the University of Alabama based on the linguistic variable approach called fuzzy approach. Chen [1] also proposes his method based on fuzzy time series to forecast the enrollments of the University of Alabama. He introduces his method and shows its advantage of reducing the calculation time and simplifying the calculation process. In another paper Chen [4] et al., use the differences of the enrollment to present a method to forecast the enrollment of the University of Alabama. In [2], Huang extends Chen's work presented in [1] and uses simplified calculations with the addition of heuristic rules to forecast the enrollments. Later in [14], Chen presents a method based on high-order fuzzy time series for forecasting the enrollment of the University of Alabama. In [8] and [9], Song et al., use the following model for forecasting university enrollment:

$$
\mathrm{Ai}=\mathrm{Ai}-1 \text { 。 } \mathrm{R},
$$

Where, Ai -1 denotes the fuzzified enrollments of year i -1 represented by a fuzzy set, Ai denotes the fuzzified enrollments of year i represented by a fuzzy set, the symbol 。denotes the Max-Min composition operator, and $\mathrm{R}$ is a fuzzy relation formed by the fuzzified enrollment of the fuzzy time series.

In [12], Sullivan et al., review the first-order time-variant fuzzy time series model and the first-order time-invariant fuzzy time series model presented by Song and Chissom, where their models are compared with each other and with a time-variant Markov model using linguistic labels with probability distributions. However, the forecasting accuracy rates of the existing fuzzy time series methods for forecasting enrollments are not good enough.

In this study, we present a new method to forecast the enrollments of the students at Philosophy Department in Jahangirnagar University, Bangladesh. The proposed method belongs to the first order time-variant methods. The rest of this paper is organized as follows. In methodology section we briefly review basic concepts of fuzzy time series from [7], [8] and [9]. Also, we describe a step by step procedure of proposed fuzzy time series method to forecast our enrollment data. In result section, we present our forecasting results of the proposed method. Finally, we made a conclusion based on our results.

\section{Methodology}

\subsection{Fundamental Concepts of Fuzzy Time Series}

In this section, we briefly review some concepts of fuzzy time series from [14, 2]. The main difference between the fuzzy time series and conventional time series is that the values of the former are fuzzy sets [4] while the values of the latter are real numbers. Roughly speaking, a fuzzy set is a class with fuzzy boundaries. Let $U$ be the universe of discourse, $\mathrm{U}=\left[\mathrm{u}_{1}, \mathrm{u}_{2}, \ldots, \mathrm{u}_{\mathrm{n}},\right\}$. A fuzzy set $\mathrm{A}$ of $\mathrm{u}$ is defined by

$$
A=f_{A}\left(u_{1}\right) / u_{1}+f_{A}\left(u_{2}\right) / u_{2}+\ldots+f_{A}\left(u_{n}\right) / u_{n},
$$


Where $\mathrm{f}_{\mathrm{A}}$ is the membership function of $\mathrm{A}, \mathrm{f}_{\mathrm{A}}: \mathrm{U} \rightarrow[0,1]$, and $f_{\mathrm{A}}\left(u_{i}\right)$ indicates the grade of membership of $u_{i}$ in $A$, where $f_{A}\left(u_{i}\right) \epsilon[0,1]$ and $1 \leq \mathrm{i} \leq \mathrm{n}$. The definitions of fuzzy time series are reviewed as follows.

Definition 3.1.1 Let $Y(t)(t=\ldots, 0,1,2, \ldots)$, a subset of $\mathbf{R}$, be the universe of discourse on which fuzzy sets $\mathrm{f}_{\mathrm{t}}(\mathrm{t})(\mathrm{i}=1,2, \ldots)$ are defined and let $F(t)$ be a collection $\mathrm{f}_{\mathrm{t}}(\mathrm{t})(\mathrm{i}=1,2, \ldots)$. Then, $F(t)$ is called a fuzzy time series on $Y(t)(\mathrm{t}=\ldots, 0,1,2, \ldots)$.

From Definition 3.1, we see that $F(t)$ can be regarded as a linguistic variable [5] and $\mathrm{f}_{\mathrm{t}}(\mathrm{t})(\mathrm{i}=1,2, \ldots)$ can be viewed as possible linguistic values of $F(t)$, where $\mathrm{f}_{\mathrm{t}}(\mathrm{t})(\mathrm{i}$ $=1,2, \ldots)$ are represented by fuzzy sets. We also can see that $F(t)$ is a function of time t, i.e., the values of $F(t)$ can be different at different times due to the fact that the universe of discourse can be different at different times. According to [14], if $F(t)$ is caused by $F(t-1)$ only, then this relationship is represented by:

$$
F(t-1) \rightarrow F(t) \text {. }
$$

Definition 3.1.2. Let $F(t)$ be a fuzzy time series. If for any time $t, F(t)=F(t-1)$ and $F(t)$ only has finite elements, then $F(t)$ is called a time-invariant fuzzy time series. Otherwise, it is called a time-variant fuzzy time series.

In [2], Song and Chissom have used the following two examples to explain the concepts of fuzzy time series using eq. (1) and they observe the weather of a certain place in North America, begin from the first day and ending with the last day of a year, where the common daily words (i.e., "good", "very good", "quite good", "very very good", "cool", "very cool", "quite cool", "hot", "very hot", "cold", "very cold", "quite cold", "very very cold", ..., etc.) are used to describe the weather conditions and these words are represented by fuzzy sets.(2) Observe the mood of a person with normal mental conditions during a period of time, where the mood of a person can be expressed according to his own feeling using fuzzy sets "good", "very good", "very very good", "really good", "bad", "not bad", "not too bad", ..., etc. In [2], Song and Chissom also pointed out that the above two examples are dynamic processes and their observations are fuzzy sets; the conventional time series models are no longer applicable to describe these processes.

\subsection{Application of the New Method for Forecasting Enrollment using Fuzzy Time Series}

In this section, we apply the new method to forecast the enrollments based on fuzzy time series. This new proposed method defines the universe of discourse and partitions-into some even and equal length intervals. Then, the chronological enrollment data in each interval are redivided and distributed statistically. After that, the linguistic values represented by fuzzy sets based on the re-divided intervals are redefined and to get the fuzzified enrollment the chronological enrollment are fuzzified. Then, fuzzy logical relationships based on the fuzzified enrollment are established. Finally, to determine the trend of the forecasting, where it goes up or down, a set of rules is used. This method is applied step by step as follows:

Step 1: We define the universe of discourse $U$ and partition it into several even and equal length intervals $\mathrm{u} 1, \mathrm{u} 2, \ldots$, and $u n$. Then assume that the universe of discourse $U=[40,90]$ is partitioned into five even and equal length intervals $u 1, u 2$, $\mathrm{u} 3, \mathrm{u} 4$, and $\mathrm{u} 5$, where $\mathrm{u} 1=[40,50], \mathrm{u} 2=[50,60], \mathrm{u} 3=[60,70], \mathrm{u} 4=[70,80]$, and $\mathrm{u} 5=[80,90]$. 
Step 2: After getting a statistics of the distribution of the chronological enrollments in each interval we sort the intervals based on the number of chronological enrollment data in each interval from the highest to the lowest. Find the interval having the largest number of historical enrollment data and divide it into four sub-intervals of equal length. Find the interval having the second largest number of historical enrollment data and divide it into three sub-intervals of equal length. Find the interval having the third largest number of historical enrollment data and divide it into two sub-intervals of equal length. Find the interval with the fourth largest number of historical enrollment data and let the length of this interval remain unchanged. If there are no data distributed in an interval, then discard this interval. For example, the distributions of the historical enrollment data in Table 1 is divided into different intervals which is are summarized in Table 2.

Table 1. Year Wise Student Enrollment Data

\begin{tabular}{|l|l|}
\hline Year & Enrollments \\
\hline 2001 & 42 \\
\hline 2002 & 68 \\
\hline 2003 & 55 \\
\hline 2004 & 64 \\
\hline 2005 & 63 \\
\hline 2006 & 68 \\
\hline 2007 & 65 \\
\hline 2008 & 72 \\
\hline 2009 & 78 \\
\hline 2010 & 76 \\
\hline 2011 & 75 \\
\hline 2012 & 84 \\
\hline 2013 & 77 \\
\hline 2014 & 78 \\
\hline
\end{tabular}

Table 2. Distribution of Enrollment Data

\begin{tabular}{|c|c|c|c|c|c|}
\hline Intervals & {$[40-50]$} & {$[50-60]$} & {$[60-70]$} & {$[70-80]$} & {$[80-90]$} \\
\hline $\begin{array}{c}\text { Number of } \\
\text { enrollment data }\end{array}$ & 1 & 1 & 5 & 6 & 1 \\
\hline
\end{tabular}

After executing this step, the universe of discourse $[40,90]$ is re-divided into the following intervals:

\begin{tabular}{|l|l|}
\hline $\mathrm{u} 1=[40-50]$ & $\mathrm{u} 2=[50-60]$ \\
\hline $\mathrm{u} 3,1=[60-63.3]$ & $\mathrm{u} 3,2=[63.3-66.6]$ \\
\hline $\mathrm{u} 3,3=[66.6-70]$ & $\mathrm{u} 4,1=[70-72.5]$ \\
\hline $\mathrm{u} 4,2=[72.5-75]$ & $\mathrm{u} 4,3=[75-77.5]$ \\
\hline $\mathrm{u} 4,4=[77.5-80]$ & $\mathrm{u} 5=[80-90]$ \\
\hline
\end{tabular}

Step 3: Defining each fuzzy set Ai based on the re-divided intervals and fuzzify the historical enrollments shown in Table 1, where fuzzy set A $i$ denotes a linguistic value of the enrollments represented by a fuzzy set, and $1 \leq i \leq 10$. For example, A1 $=$ very very very few, $\mathrm{A} 2=$ very very few, $\mathrm{A} 3=$ very few, $\mathrm{A} 4=$ few, $\mathrm{A} 5=$ 
moderate, $\mathrm{A} 6=$ many, $\mathrm{A} 7=$ many many, $\mathrm{A} 8=$ very many, $\mathrm{A} 9=$ too many, $\mathrm{A} 10=$ too many many, defined as follows [13]:

$$
\mathrm{A} 1=1 / \mathrm{u} 1+0.5 / \mathrm{u} 2+0 / \mathrm{u} 3,1+0 / \mathrm{u} 3,2+0 / \mathrm{u} 3,3+0 / \mathrm{u} 4,1+0 / \mathrm{u} 4,2+0 / \mathrm{u} 4,3+0 / \mathrm{u} 4,4+
$$
$0 / \mathrm{u} 5$,

$$
\mathrm{A} 2=0.5 / \mathrm{u} 1+1 / \mathrm{u} 2+0.5 / \mathrm{u} 3,1+0 / \mathrm{u} 3,2+0 / \mathrm{u} 3,3+0 / \mathrm{u} 4,1+0 / \mathrm{u} 4,2+0 / \mathrm{u} 4,3+0 / \mathrm{u} 4,4
$$
$+0 / \mathrm{u} 5$,

$$
\begin{aligned}
& \mathrm{A} 3=0 / \mathrm{u} 1+0.5 / \mathrm{u} 2+1 / \mathrm{u} 3,1+0.5 / \mathrm{u} 3,2+0 / \mathrm{u} 3,3+0 / \mathrm{u} 4,1+0 / \mathrm{u} 4,2+0 / \mathrm{u} 4,3+0 / \mathrm{u} 4,4 \\
+ & 0 / \mathrm{u} 5
\end{aligned}
$$

$$
\mathrm{A} 4=0 / \mathrm{u} 1+0 / \mathrm{u} 2+0.5 / \mathrm{u} 3,1+1 / \mathrm{u} 3,2+0.5 / \mathrm{u} 3,3+0 / \mathrm{u} 4,1+0 / \mathrm{u} 4,2+0 / \mathrm{u} 4,3+0 / \mathrm{u} 4,4
$$
$+0 / \mathrm{u} 5$,

$\mathrm{A} 5=0 / \mathrm{u} 1+0 / \mathrm{u} 2+0.5 / \mathrm{u} 3,1+1 / \mathrm{u} 3,2+0.5 / \mathrm{u} 3,3+0 / \mathrm{u} 4,1+0 / \mathrm{u} 4,2+0 / \mathrm{u} 4,3+0 / \mathrm{u} 4,4$ $+0 / \mathrm{u} 5$,

$$
\mathrm{A} 6=0 / \mathrm{u} 1+0 / \mathrm{u} 2+0 / \mathrm{u} 3,1+0.5 / \mathrm{u} 3,2+1 / \mathrm{u} 3,3+0.5 / \mathrm{u} 4,1+0 / \mathrm{u} 4,2+0 / \mathrm{u} 4,3+0 / \mathrm{u} 4,4
$$
$+0 / \mathrm{u} 5$,

$\mathrm{A} 7=0 / \mathrm{u} 1+0 / \mathrm{u} 2+0 / \mathrm{u} 3,1+0 / \mathrm{u} 3,2+0.5 / \mathrm{u} 3,3+1 / \mathrm{u} 4,1+0.5 / \mathrm{u} 4,2+0 / \mathrm{u} 4,3+0 / \mathrm{u} 4,4$ $+0 / \mathrm{u} 5$,

$$
\mathrm{A} 8=0 / \mathrm{u} 1+0 / \mathrm{u} 2+0 / \mathrm{u} 3,1+0 / \mathrm{u} 3,2+0 / \mathrm{u} 3,3+0.5 / \mathrm{u} 4,1+1 / \mathrm{u} 4,2+0.5 / \mathrm{u} 4,3+0 / \mathrm{u} 4,4
$$
$+0 / \mathrm{u} 5$,

A $9=0 / \mathrm{u} 1+0 / \mathrm{u} 2+0 / \mathrm{u} 3,1+0 / \mathrm{u} 3,2+0 / \mathrm{u} 3,3+0 / \mathrm{u} 4,1+0.5 / \mathrm{u} 4,2+1 / \mathrm{u} 4,3+0.5 / \mathrm{u} 4,4$ $+0 / \mathrm{u} 5$

$$
\mathrm{A} 10=0 / \mathrm{u} 1+0 / \mathrm{u} 2+0 / \mathrm{u} 3,1+0 / \mathrm{u} 3,2+0 / \mathrm{u} 3,3+0 / \mathrm{u} 4,1+0 / \mathrm{u} 4,2+0.5 / \mathrm{u} 4,3+1 / \mathrm{u} 4,4
$$
$+0.5 / \mathrm{u} 5$,

For simplicity, the membership values of fuzzy set Ai either are $0,0.5$ or 1 , where $1 \leq i \leq 10$. Then, fuzzify the historical enrollments shown in Table 1 based on [15] and the linguistic values of the enrollments A1, A2, ., A10. The reason for fuzzifying the historical enrollments into fuzzified enrollments is to translate crisp values into fuzzy sets to get a fuzzy time series.

Step 4: Establishing fuzzy logical relationships based on the fuzzified enrollment: where the fuzzy logical relationship " $A j \rightarrow A q$ " denotes " if the fuzzified enrollments of year n-1 is $A j$, then the fuzzified enrollments of year $\mathrm{n}$ is $A q$ ". For example, based on the fuzzify historical enrollments obtained in Step 3, we can get the fuzzy logical relationships as shown in Table 3.

Table 3. Fuzzy Logical Relationships

\begin{tabular}{|l|l|l|l|l|}
\hline A1->A5 & A5->A2 & A2->A4 & A4->A3 & A3->A5 \\
\hline A5->A4 & A4->A6 & A6->A9 & A9->A8 & A8->A7 \\
\hline A7->A10 & A10->A8 & A8->A9 & & \\
\hline
\end{tabular}

Step 5: Dividing each interval derived in Step 2 into four subintervals of equal length, where the 0.25-point and 0.75-point of each interval are used as the upward and downward forecasting points of the forecasting. Use the following rules to determine whether the trend of the forecasting goes up or down and to forecast the 
enrollment. Assume that the fuzzy logical relationship is $\mathrm{Ai} \rightarrow \mathrm{Aj}$, where Ai denotes the fuzzified enrollment of year $n-1$ and $A j$ denotes the fuzzified enrollment of year $n$, then (1) If $j>i$ and the difference of the differences of the enrollments between years $n-1$ and n-2 and between years $n-2$ and n-3 is positive, then the trend of the forecasting will go up, and we use the following Rule 2 to forecast the enrollments; (2) If $j>i$ and the difference of the differences of the enrollments between years $n$ 1 and $n-2$ and between years $n-2$ and n-3 is negative, then the trend of the forecasting will go down, and we use the following Rule 3 to forecast the enrollments; (3) If $\mathrm{j}<\mathrm{i}$ and the difference of the differences of the enrollments between years n-1 and n-2 and between years n-2 and n-3 is positive, then the trend of the forecasting will go up, and we use the following Rule 2 to forecast the enrollments; (4) If $\mathrm{j}<\mathrm{i}$ and the difference of the differences of the enrollments between years n-1 and n-2 and between years n-2 and n-3 is negative, then the trend of the forecasting will go down, and we use the following Rule 3 to forecast the enrollments; (5) If $\mathrm{j}=\mathrm{i}$ and the difference of the differences of the enrollments between years n-1 and n-2 and between years n-2 and n-3 is positive, then the trend of the forecasting will go up, and we use the following Rule 2 to forecast the enrollments; (6) If $\mathrm{j}=\mathrm{i}$ and the difference of the differences of the enrollments between years n-1 and n-2 and between years n-2 and n-3 is negative, then the trend of the forecasting will go down, and we use the following Rule 3 to forecast the enrollments, where Rule 1, Rule 2 and Rule 3 are shown as follows: Rule 1: When forecasting the enrollment of year 2003, there are no data before the enrollments of year 2001, therefore we are not able to calculate the difference of the enrollments between years 2001 and 2000 and the difference of the differences between years 2002 and 2001 and between years 2001 and 2000. Therefore, if |(the difference of the enrollments between years 2002 and 2001) $\mid / 2>$ half of the length of the interval corresponding to the fuzzified enrollment $\mathrm{Aj}$ with the membership value equal to 1 , then the trend of the forecasting of this interval will be upward, and the forecasting enrollment falls at the 0.75 -point of this interval; if |(the difference of the enrollments between years 2002 and 2001)|/2 = half of the length of the interval corresponding to the fuzzified enrollment $\mathrm{Aj}$ with the membership value equal to 1 , then the forecasting enrollmentfalls at the middle value of this interval; if |(the difference of the enrollments between years 2002 and 2001)|/2< half of the length of the interval corresponding to the fuzzified enrollment $\mathrm{Aj}$ with the membership value equal to 1 , then the trend of the forecasting of this interval will be downward, and the forecasting enrollment falls at the 0.25-point of the interval. Rule 2: If (|the difference of the differences between years $n-1$ and $n-2$ and between years $n-2$ and $\mathrm{n}-3 \mid \times 2+$ the enrollments of year n-1) or (the enrollments of year $n-1-$ the difference of the differences between years $n-1$ and $n-2$ and between years $n-2$ and $\mathrm{n}-3 \mid \times 2$ ) falls in the interval corresponding to the fuzzified enrollment $\mathrm{Aj}$ with the membership value equal to 1 , then the trend of the forecasting of this interval will be upward, and the forecasting enrollment falls at the 0.75 -point of the interval of the corresponding fuzzified enrollment $\mathrm{Aj}$ with the membership value equal to 1 ; if (|the difference of the differences between years $n-1$ and $n-2$ and between years $n-2$ and $n-3 \mid / 2+$ the enrollments of year n-1) or (the enrollments of year $n-1$ - |the difference of the differences between years $n-1$ and n-2 and between years $n-2$ and $\mathrm{n}-3 \mid / 2$ ) falls in the interval of the corresponding fuzzified enrollment $\mathrm{Aj}$ with the membership value equal to 1 , then the trend of the forecasting of this interval will be downward, and the forecasting value falls at the 0.25 -point of the interval of the corresponding fuzzified enrollment $\mathrm{Aj}$ with the membership value equal to 1 ; if neither is the case, then we let the forecasting enrollment be the middle value of the 
interval corresponding to the fuzzified enrollment $\mathrm{Aj}$ with the membership value equal to 1.

Rule 3: If (|the difference of the differences between years $n-1$ and $n-2$ and between years $n-2$ and $n-3 / / 2+$ the enrollments of year n-1) or (the enrollments of year $n-1$ - |the difference of the differences between years $n-1$ and $n-2$ and between years $n-2$ and $n-3 \mid / 2$ ) falls in the interval of the corresponding fuzzified enrollment $\mathrm{Aj}$ with the membership value equal to 1 , then the trend of the forecasting of this interval will be downward, and the forecasting enrollment falls at the 0.25 -point of the interval corresponding to the fuzzified enrollment $\mathrm{Aj}$ with the membership value equal to 1 ; if (|the difference of the differences between years $n-1$ and $n-2$ and between years $n-2$ and $n-3 \mid \times 2+$ the enrollment of year n-1) or (the enrollment of year n-1 - the difference of the differences between years $n-1$ and $n-2$ and between years $n-2$ and $n-3 \mid \times 2$ ) falls in the interval corresponding to the fuzzified enrollment $\mathrm{Aj}$ with the membership value equal to 1 , then the trend of the forecasting of this interval will be upward, and the forecasting enrollment falls at the 0.75-point of the interval corresponding to the fuzzified enrollment $\mathrm{Aj}$ with the membership value equal to 1 ; if neither is the case, then we let the forecasting enrollment be the middle value of the interval corresponding to the fuzzified enrollment $\mathrm{Aj}$ with the membership value equal to 1 .

\section{Results of Proposed Forecasting Method}

We have implemented the proposed method. Table 4 summarizes the forecasting results of the proposed method from 2002 to 2014, where the universe of discourse is divided into 10 intervals and the interval with the largest number of historical enrollment data is divided into 4 sub-intervals of equal length.

Table 4. Actual and Forecasted Enrollment

\begin{tabular}{|c|c|c|c|}
\hline Year & $\begin{array}{c}\text { Actual } \\
\text { Enrollment }\end{array}$ & $\begin{array}{c}\text { Fuzzy } \\
\text { Enrollment }\end{array}$ & $\begin{array}{c}\text { Forecasted } \\
\text { Enrollment }\end{array}$ \\
\hline 2001 & 42 & A1 & \\
\hline 2002 & 68 & A5 & 68.3 \\
\hline 2003 & 55 & A2 & 59.975 \\
\hline 2004 & 64 & A4 & 64.95 \\
\hline 2005 & 63 & A3 & 66.45 \\
\hline 2006 & 68 & A5 & 86.3 \\
\hline 2007 & 65 & A4 & 59.975 \\
\hline 2008 & 72 & A6 & 66.45 \\
\hline 2009 & 78 & A9 & 78.75 \\
\hline 2010 & 76 & A8 & 76.25 \\
\hline 2011 & 75 & A7 & 76.25 \\
\hline 2012 & 84 & A10 & 85 \\
\hline 2013 & 77 & A $~$ & 76.25 \\
\hline 2014 & 78 & A9 & 76.25 \\
\hline
\end{tabular}

We use the mean square error (MSE) to measure the performance of the forecasting methods, where the mean square error is calculated as follows: sum of the squared differences between actual enrollments for year $i$, and forecasted enrollments of year $i$, divided by the total number of observations used in calculation. From Table 4, we calculate the forecasting results of the proposed method with that of the actual data. A graphical representation in Fig. 1 also indicates the performance of the proposed method clearly. 


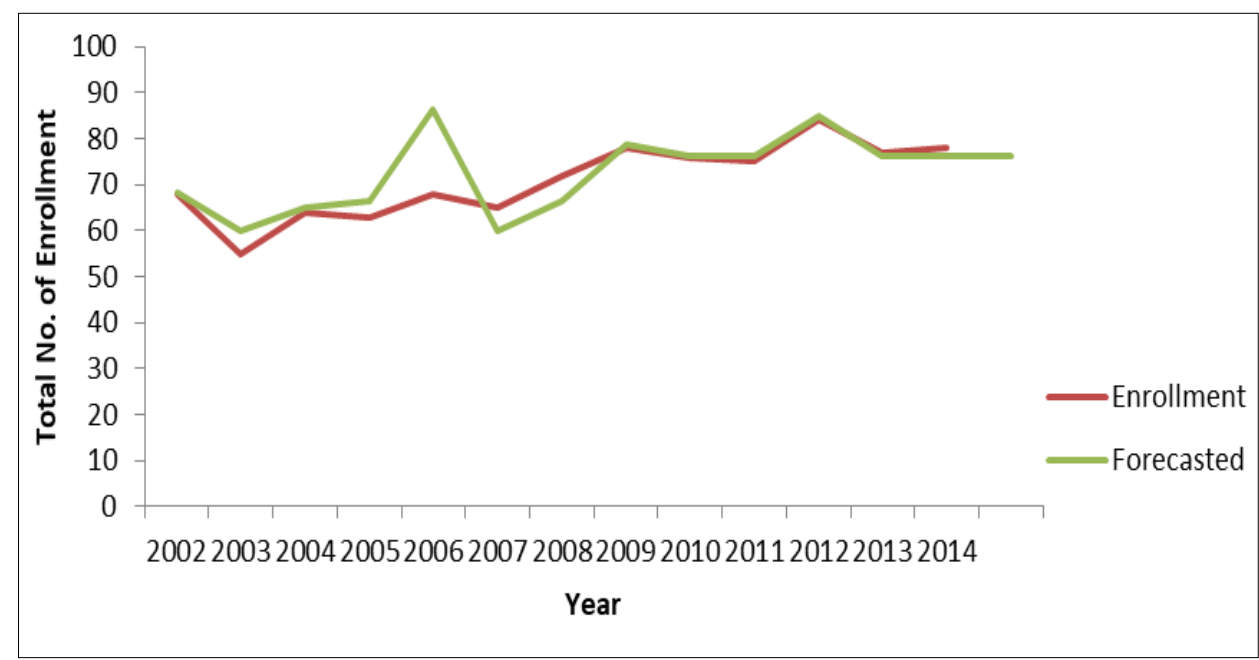

Figure 1. Predictive Performance of Proposed Model for Student Enrollment

Figure 1 indicates that, difference between actual enrollment and forecasted enrollment values are marginal except the year 2006. Result of MSE indicates that, forecasted values are less than the threshold value of $10 \%$.

\section{Conclusion}

This study presents Chen's modified fuzzy method to forecast student enrolment based on fuzzy time series, where the data are collected from philosophy department at Jahangirnagar University. Mean square error (MSE) has been used as a performance measure to illustrate and test the forecasting processes and method. From the illustrative example, we can see that the proposed method can make good forecasts of enrollments data series with a performance criteria MSE which is less than the threshold value of $10 \%$. Findings of this study are critical for the university authority in adopting appropriate forecasting technique and thereby formulating apposite policy making for future.

\section{Acknowledgment}

Authors express their gratitude to the University Grant Commission (UGC), Bangladesh as this research is funded by UGC in the academic year of 2015-16.

\section{References}

[1] S. M. Chen, "Forecasting enrollments based on fuzzy time series", Fuzzy Sets and Systems, vol. 81, pp. 311-319.

[2] S. Choudhuri, R. C. Standridge, C. Griffin and W. Wenner, "Enrollment Forecasting for an Upper Division General Education Component", Proceedings of the 37th ASEE/IEEE Frontiers in Education Conference, Milwaukee, (2007) October 10-13, pp. T3E-25-T3E-28.

[3] A. N. Haris, M. Abdullah, T. A. Othman and A. F. Rahman, "Application of Forecasting Technique for Students Enrollment", Knowledge Management International Conference (KMICe), Malaysia, (2014) August 12-15, pp. 655-662.

[4] J. R. Hwang, S. M. Chen and C. H. Lee, "Handling forecasting problems using fuzzy time series", Fuzzy Sets and Systems, vol. 100, (1998), pp. 217-228.

[5] G. J. Klir and B. Yuan, "Fuzzy Sets and Fuzzy Logic: Theory and Applications", Prentice Hall, New Jersey, U.S.A., (1995).

[6] Q. R. Lavilles and B. J. M. Arcilla, "Enrollment Forecasting for School Management System", International Journal of Modeling and Optimization, doi:10.7763/IJMO.2012.V2.183, vol. 2, no. 5, (2012), pp. 563-566.

[7] Q. Song and B. S. Chissom, "Fuzzy time series and its models", FuzzySets and Systems, vol. 54, (1993), pp. 269-277. 
[8] Q. Song and B. S. Chissom, "Forecasting enrollments with fuzzy time series - Part I", Fuzzy Sets and Systems, vol. 54, (1993), pp. 1-9.

[9] Q. Song and B. S. Chissom, "Forecasting enrollments with fuzzy time series - Part II", Fuzzy Sets and Systems, vol. 62, (1994), pp. 1-8.

[10] Q. Song and R. P. Leland, “Adaptive learning defuzzification techniques and applications”, Fuzzy Sets and Systems, vol. 81, (1996), pp. 321-329.

[11] Q. Song, "A note on fuzzy time series model selection with sample autocorrelation functions", Cybernetics and Systems: An International Journal, vol. 34, (2003), pp. 93-107.

[12] J. Sullivan and W. H. Woodall, "A comparison of fuzzy forecasting and Markov modeling", Fuzzy Sets and Systems, vol. 64, (1994), pp. 279-293.

[13] H. Tatli and Z. Sen, "A new fuzzy modeling approach for predicting the maximum daily temperature from a time series", Turkish Journal of Engineering and Environmental Sciences, vol. 23, no. 3, (1999), pp. 173-180.

[14] J. Ward, "Forecasting Enrollment to Achieve Institutional Goals", College and University Journals, (2007), pp. 41-46.

[15] L. X. Wang and J. M. Mendel, "Generating fuzzy rules by learning from examples", IEEE Transactions on Systems, Man, and Cybernetics, vol. 22, (1992), pp. 1414-1427.

[16] L. A. Zadeh, "Fuzzy sets", Information and Control, vol. 8, (1965), pp. 338-353.

[17] L. A. Zadeh, K. S. Fu, S. Tanaka and M. Shimura, "Fuzzy sets and their application to Cognitive and Decision Process", Academic Press, (1975).

\section{Authors}

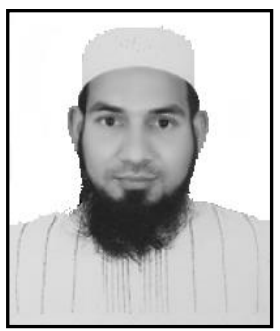

Muhammad Ullah, he is an Assistant Professor in the Department of Philosophy at Jahangirnagar University, Savar, Bangladesh. He completed his M.A degree from Dhaka University, Bangladesh in 2009. His research interests focus on Philosophy of Education, Educational Statistics, Education Policy and Critical thinking.

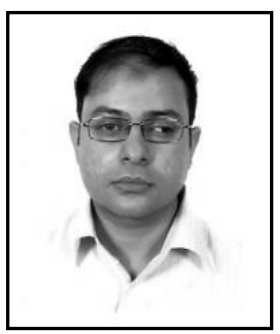

Farhadur Reza, he is serving as Assistant Professor in the Department of Urban and Regional Planning, Jahangirnagar University, Dhaka, Bangladesh. He obtained Master Degree in Urban and Regional Planning from Jahangirnagar University. His research interest lies in application of Quantitative Techniques in the field of Urban Planning, Environmental Planning, Transportation Planning, Time Series Analysis.

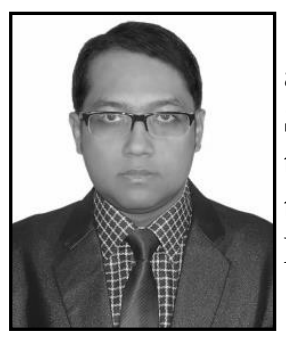

AzizurRahman, he is Assistant Professor in Statistics department at Jahangirnagar University, Dhaka, Bangladesh. He finished his M. Sc. Study from Jahangirnagar University, in September, 2010, with the major in Statistics. His research interests focus on statistical theory and inference, Biostatistics, Neural Network methodologies, Econometrics, Fuzzy Time series analysis, Educational Statistics.

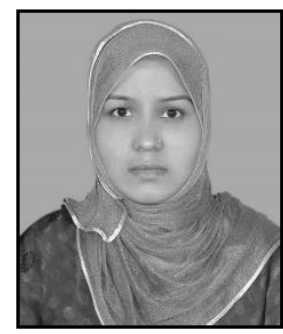

Mariam Akter, she finished her M. Sc. Study from Jahangirnagar University, in September, 2012, with the major in Statistics. Her research interests focus on statistical theory and inference, Biostatistics, demography, Econometrics, Time series analysis, simulation. 
International Journal of Advanced Science and Technology Vol.106 (2017) 